\title{
Fatores que influenciam a imagem da marca: um estudo de mensuração aplicado à marca Harley-Davidson*
}

Ari Melo Mariano ${ }^{1}$ Kamila Ferreira Rocha Silva ${ }^{2}$ Maíra Rocha Santos ${ }^{3}$
Recebido em: 10/04/2016.

Aprovado em: 14/09/2016.

1 Faculdade de Agronomia e Medicina Veterinária, Brasília. Pós Doutor em Negócios Internacionais e Metodologia Cientifica . Doutor em Administração peloa UFBA, Doutor em Negócios Internacionais pela Universidade de Sevilla, Espanha, Mestrado en gestão e direção de empresas pela Universidade de Sevilla-España, MBA em Direito do Consumidor Europeu pela Universidade de Sevilla, Graduado em Marketing pelo Centro Universitario da Bahia.

2 Graduanda do Centro Universitário de Brasília - UniCEUB.

3 Graduanda do Centro Universitário de Brasília - UniCEUB.

\section{Factors influencing brand image: a measurement study applied to the Harley-Davidson brand}

\section{Resumo}

Este estudo teve como objetivo identificar o grau de influência dos fatores antecedentes à imagem da marca. Como base teórica, foram abordados alguns conceitos de vantagem competitiva, marketing, conceitos delimitadores da marca, valoração da marca e metrificação explorando os indicadores da marca. A pesquisa de caráter descritivo foi uma adaptação do modelo em espanhol de Ramos (2002). Foi aplicado um questionário a 381 estudantes de uma instituição de ensino de nível superior sobre a imagem da marca e seus antecedentes aplicados a Harley-Davidson. $\mathrm{O}$ instrumento e modelo foram validados para Língua Portuguesa com coeficiente de confiabilidade $\mathrm{fc}=0,85$. Os resultados neste estudo sugerem que o fator de maior influencia sobre a imagem da marca é o compromisso do consumidor (16\%), seguido da confiança (11,5\%) e da percepção da marca (10\%). Sendo assim, quanto mais significativas forem as três dimensões melhor será a imagem da marca.

Palavras-chave: Vantagem competitiva. Métrica de marketing. Valor da marca. Marca. Instrumento validado.

\section{Abstract}

This study aimed to identify the degree of influence of factors antecedent to the brand image. As a theoretical basis, some concepts of competitive advantage, marketing, brand delimiters concepts, brand valuation and metrification were explored, exploring brand indicators. The descriptive research was an adaptation of the Spanish model of Ramos (2002). A questionnaire was administered to 381 students of a higher education institution on the brand image and background applied to Harley-Davidson. The instrument and model were validated for Portuguese Language with reliability coefficient $\mathrm{fc}=0.85$. The results in this study suggest that the factor that most influences the brand image is consumer commitment (16\%), followed by trust (11.5\%) and brand perception (10\%). Therefore, the more significant the three dimensions, the better the brand image. Keywords: Competitive advantage. Marketing metrics. Brand value. Brand. Validated instrument. 


\section{Introdução}

A globalização alterou o mercado e a forma de competir das grandes organizações, esse crescimento que fez as empresas saírem do âmbito local para o global passou a exigir das organizações uma capacidade maior de formular e implementar estratégias para alcançar objetivos e superar os novos desafios que o mercado globalizado oferece. (CAMARGOS; DIAS, 2003).

Nesse novo cenário mundial, a estratégia de marketing tem se tornado uma grande aliada para o desenvolvimento de atividades e tomadas de decisão. Isso porque, por meio do marketing, as organizações conseguem uma melhor interação com o meio externo, dialogando com diversos públicos, principalmente seus consumidores (TOALDO; LUCE, 2006).

Faria e Guedes (2005) explicam que foi o poder do consumidor que permitiu a consolidação de um mundo globalizado. Com esse novo grande mercado, as empresas não podem mais focar apenas na área financeira ou em derrotar seus concorrentes, com a globalização, gerar valor e desenvolver uma visão paralela de quem é o consumidor e o que querem passou a ter uma grande importância para as organizações.

Antes da globalização, os ativos tangíveis de uma empresa eram os bens mais valiosos para uma organização (BUAINAIN; CARVALHO, 2000), com o surgimento dessa nova realidade global, o sucesso de uma marca forte e com um alto valor de mercado tem sido mais importante que os ativos tangíveis dessa empresa, já que o consumidor percebe uma marca por meio de vários fatores, geralmente, intangíveis, dificilmente vai se interessar pelos elementos materiais que essa empresa possui (LANZA; CASIELLES; ARGÜELLES, 2002).

As organizações já estão percebendo o impacto de suas marcas até mesmo quando vão calcular o valor de sua venda. Cada vez mais, grandes empresas possuem valores de venda maiores que todos os ativos materiais somados. Segundo uma pesquisa feita entre 1978 e 1998 pela economista americana Margaret Blair, da Brookings Institution, o patrimônio físico das organizações estudadas correspondia a $80 \%$ do valor de mercado da empresa. Passados 20 anos, esse valor passou a ser de, apenas, 20\% para os bens tangíveis dessas organizações (SULLIVAN JÚNIOR; SULLIVAN, 2000).

Segundo Pedro (1999), a partir da década de 80, as marca. Desde então começaram a perceber que os valores intangíveis ultrapassavam os valores tangíveis de uma organização.

Por compreender que a marca se tornou um dos ativos intangíveis mais valiosos que as empresas possuem, o Branding, que segundo Martins (2006) são ações que "levam as marcas além da sua natureza econômica, passando a fazer parte da cultura, e influenciar a vida das pessoas", tem se tornado prioridade dentro das empresas. Mas essa ferramenta ainda é um desafio para os executivos de marketing, pois traduzir a imagem de uma marca em termos financeiros, ainda é um obstáculo, sendo muitas vezes questionado se os resultados são confiáveis ou, apenas, baseados na intuição desses profissionais.

Medir a imagem de uma marca é importante para garantir vantagem competitiva para uma organização, saber se o consumidor compra aquele produto por causa do preço e conveniência ou se existe lealdade à marca mesmo existindo concorrentes com preço, conveniência e características iguais ou superiores. Isso define a competitividade da empresa no mercado (MAGALHÃES, 2006).

Este estudo justifica-se, socialmente, ao especificar as variáveis mais importantes para gerar uma imagem de marca satisfatória, ampliando novos campos de trabalho e remunerando melhor o profissional que passa a ter um instrumento para medir o resultado de suas ações. Para a administração, a justificativa parte da necessidade que as empresas possuem de conseguir identificar os fatores antecedentes a imagem da marca, assim conseguirá descobrir onde focar seus esforços. Cientificamente, é um tema que tem crescido em número de publicações e citações, tendo no ano de 2014 um aumento considerável como revela o Anexo A (em anexo) segundo a base de dados Scientific Electronic Library Online.

Assim, o estudo da imagem da marca se traduz na possibilidade de gerar valor competitivo para a empresa. Observando o contexto surge o problema: Quais fatores antecedentes que mais influenciam a da imagem da marca?

O objetivo deste artigo é identificar o grau de influência dos fatores antecedentes à imagem da marca. Para alcançar o objetivo geral, foi necessário dividi-lo em objetivos específicos como: apresentar os fatores antecedentes da imagem da marca, mapear as variáveis que estejam ligadas diretamente ao desempenho superior e a alta percepção do consumidor e, por fim, testar um modelo validado para mensuração do grau de influência 
através da marca Harley-Davidson. Este estudo é descritivo, com abordagem quantitativa através da técnica de equações estruturais, por meio do software Smart Partial Least Square (SPLS). Para atingir esses objetivos, serão identificadas as variáveis do estudo na literatura, buscando entender os fatores antecedentes da imagem da marca e o desempenho superior, em seguida se apresentará a metodologia, resultados e considerações finais.

\section{Desenvolvimento}

\subsection{Vantagem competitiva}

No panorama empresarial atual, existe uma busca frequente pela competitividade, e isto é constantemente relacionado ao fator humano, social e ambiental das empresas. Esses fatores merecem atenção, pois são elementos fundamentais para a conquista de vantagem competitiva para as organizações (FEITOSA, 2009).

A vantagem competitiva começou a aparecer na literatura de estratégia em 1965 através de Ansoff, que descreveu como "a vantagem de perceber, de forma proativa, tendências de mercado à frente dos concorrentes e de ajustar a oferta em função dessa antecipação.” Mas foi só ao final dos anos 70 que a expressão passou a interessar as organizações e se tornar uma forte ferramenta estratégica. Então, em 1986, Ghemawat demonstra que a inovação de produtos, os processos de produção e o marketing das empresas são fatores que ligados formam a estrutura da vantagem competitiva (VASCONCELOS; BRITO, 2004).

Para Vasconcelos e Cyrino (2000), é possível dividir a questão da vantagem competitiva, originaria das teorias de estratégia empresarial, em dois eixos, como mostra a figura 1 :

Figura 1 - As correntes explicativas da vantagem competitiva

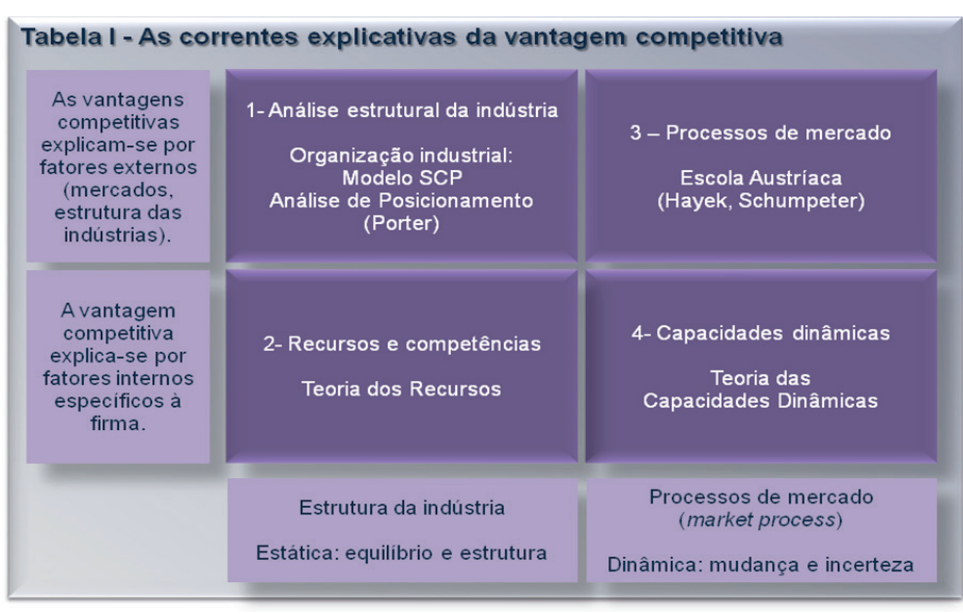

Fonte: Vasconcelos e Cyrino, 2000.
O primeiro considera a concepção de origem da vantagem competitiva, podendo considerar o sucesso competitivo como um fenômeno oriundo de características internas da empresa ou atribuindo esse posicionamento ao cenário externo, ou seja, o mercado e seus concorrentes. Já o segundo eixo é baseado na concorrência, em que alguns pesquisadores focam em uma visão mais estática e estrutural, constituída na percepção de equilíbrio econômico, enquanto outros acreditam em aspectos mais dinâmicos e mutáveis, levando em conta a inovação e o desequilibro.

Considerando-se, então, as características internas das organizações, percebe-se que, para que exista uma vantagem competitiva eficaz, faz-se necessária a manutenção contínua de um conjunto de recursos como conhecimento, informação, ativos, competências, atributos, processos organizacionais, dentre outros. Essas características podem ser relacionadas aos ativos intangíveis e esses recursos se bem conduzidos podem levar as organizações a alcançar lucros além do comum e a consolidar a vantagem competitiva de suas empresas (KAYO, et al., 2006).

Segundo Toaldo e Luce (2006), para se obter vantagem competitiva, é necessário, também, focar em atividades que gerem valor para o consumidor em relação às ofertas dos concorrentes e isso acontece por meio da formulação e da implementação de ações que visam ao entendimento e a iniciativas para garantir esse posicionamento, como as ações de marketing.

\subsection{Marketing}

O marketing é uma das principais ferramentas para a conquista de vantagem competitiva para as empresas, com novos conceitos cada vez mais difundidos no meio empresarial que orientam as empresas para o mercado e, ainda, para a criação de valor para o cliente (FEITOSA, 2009).

Segundo Kotler (1998, p. 27), “marketing é um processo social e gerencial pelo qual indivíduos e grupos obtêm o que necessitam e desejam através da criação, oferta e troca de produtos de valor com outros".

Para entender como o marketing funciona, Pereira, Toledo, G. e Toledo, L. (2009) apresentam 3 dimensões do marketing:

Dimensão Funcional $\rightarrow$ Dimensão Filosófica $\rightarrow$ Dimensão Gerencial

A dimensão funcional estabelece que a função do 
marketing seja compreender os relacionamentos de troca e esse processo de troca não é tão simples, as pessoas tendem a se envolver nesse processo quando percebem que terão sua satisfação atendida. Assim, o marketing tem como objetivo a analise o estimulo, a promoção e a troca de valores entre organizações e indivíduos, pelo estabelecimento de relacionamentos duradouros.

Já a dimensão filosófica retrata a direção tomada pela empresa e esta será a base para as ações que serão adotadas. Dentre varias opções de orientação empresarial, existe a orientação para o mercado, que se refere ao momento em que a empresa adota a estratégia de focar no cliente na mesma proporção que foca na concorrência, ou seja, toda decisão terá como base os desejos e necessidades do consumidor com o objetivo de colocar a empresa em um patamar superior ao que se encontra o concorrente.

Por fim, a dimensão gerencial representa a atividade operacional, que coloca em pratica as estratégias e a busca pelos objetivos encontrados nas outras duas dimensões, ou seja, transforma a teoria em ações administrativas.

Analisando-se, então, as três dimensões, é possível traçar uma linha para o marketing em que primeiramente, com a dimensão filosófica, escolhe-se uma orientação empresarial, que pode ser baseada na competitividade, no relacionamento com o cliente, voltada para o mercado, para a responsabilidade social, ou várias outras direções possíveis. Posteriormente, é levada em conta a função de troca do marketing, com a dimensão funcional e seus objetivos e, por fim, ocorre a prática do processo administrativo do marketing.

Toaldo e Luce (2006) enfatizam a importância de perceber a estratégia de marketing como um processo que gera valor ao mercado, já que o foco do marketing não é, apenas, o objeto de transação e sim as atividades e pessoas envolvidas durante todo o processo efetivo. Em uma empresa, os resultados das ações de Marketing estão diretamente relacionados à marca, uma vez que, por meio dessas estratégias, estabelece-se um posicionamento desta.

\subsection{Marca}

Segundo Costa e Almeida (2012), gerar vantagem competitiva é o que cria valor para uma empresa, isso está relacionado aos ativos intangíveis que a empresa possui, como sua marca.
A American Marketing Association (AMA) tem como definição de marca "um nome, termo, sinal, símbolo ou design, ou uma combinação de tudo isso, destinado a identificar os produtos ou serviços de um fornecedor ou grupo de fornecedores para diferenciá-los dos de outros concorrentes." Ou seja, a marca acrescenta características que diferencia um produto ou serviço de outros semelhantes.

Quando uma marca é percebida pelo cliente de forma fácil e imediata, ela é considerada com um alto nível de notoriedade e isso acaba gerando, na mente do consumidor, uma maior preferência por essas marcas. Assim, marcas bem conhecida possuem uma vantagem competitiva bem maior em relação à preferência do consumidor, já que, com o aumento da consciência da marca na mente do consumidor, as chances de escolher por essa empresa, também, aumenta, agregando valor a ela (AAKER, 1991). As associações à marca alcançam, então, um grau elevado e com um grande poder de influenciar na decisão do consumidor. Além disso, o consumidor passa a acumular experiências satisfatórias com a empresa, isso pode acontecer de forma direta ou por meio dos meios de comunicação existentes.

Segundo Kotler e Keller (2006), as marcas são divididas em "Funcionais, racionais ou tangíveis - isto é, relacionada ao desempenho do produto. E podem também ser mais simbólicas, emocionais ou intangíveis - isto é, relacionadas ao que a marca representa”.

Tavares (1998) explica que a marca é a responsável por estabelecer um relacionamento entre o consumidor e o produto, sendo o produto o que a empresa produz e a marca o que o consumidor compra. O produto por si só não tem voz, além de ter sua duração limitada, já a marca é quem da o real significado, não tem prazo de validade e tem o poder de se comunicar com o consumidor.

Essa comunicação acontece porque o consumidor, ao adquirir uma marca, espera que o uso daquele produto possa lhe proporcionar benefícios, uma boa experiência e uma resposta emocional positiva. Assim, é possível dizer que a marca é capaz de proporcionar experiências e lembranças ao consumidor, e isso é um diferencial competitivo, criando, assim, o Branding que atribui a um produto ou serviço o poder de uma marca (PEREIRA, 2005).

\subsubsection{Valor da marca}

O significado de uma marca acontece pela percepção do consumidor, por essa razão, o sucesso de uma marca depende da aceitação ou rejeição das ideias que os 
responsáveis pelo marketing geram (SCHULTZ; BARNES, 2001). Esse é o valor da marca, quando o consumidor avalia todos os custos e benefícios que um produto ou serviço lhe proporcionarão. Uma marca forte se sustenta de alguma forma na memória do consumidor, este por já estar familiarizado com a marca, pode ter estímulos externos que permitem uma associação favorável e única dessa marca. Este retorno favorável, é capaz de reduz os custos, aumentar a receita e os lucros (TAVARES, 1998).

Assim, o conceito de brand equity pode ser colocado como um valor adicional da marca, sob a visão do consumidor e da empresa que a possui, para caracterizar seus produtos e/ou serviços e a própria organização (SAMPAIO, 2002). Para Rust, Zeithaml e Lemon (2001), o valor é a qualidade levada em consideração, como o preço, já o valor da marca para o consumidor é a avaliação particular do cliente além do valor percebido.

Assim, ao observar a marca, existe um valor intangível representado pela imagem da marca juntamente ao mercado. Essa interação da marca com o mercado acontece para os fornecedores, os clientes e concorrentes.

\subsubsection{Mensuração da marca}

Dentre as inúmeras métricas de marketing existentes, que servem para os mais variados segmentos de mercado, as métricas que avaliam o valor da marca são consideradas as mais importantes para a orientação estratégica de marketing (PUPO; BOTELHO, 2011).

Ramos (2002) cita quatro autores que reuniram os principais indicadores relacionados à metrificação em relação à marca. Irmscher (1993) tem como objetivo a avaliação da marca por meio de uma série de indicadores de garantia prestada pela marca para consumidores, distribuidores e da própria empresa.

Martin e Brown (1990) aportam indicadores como fidelidade, qualidade percebida, associações e reconhecimento do nome da marca. Em relação a mesma linha de percepção dos consumidores Lassar, Mittal e Sharma (1995) consideram como determinantes da metrificação um valor focado na conscientização da marca, desempenho, imagem social e qualidade percebida.

Por fim, François e MacLachlan (1995) fazem uma diferenciação entre as medidas de natureza intrínseca e extrínseca. A primeira demonstra a força da marca em relação ao comportamento e às preferências percebidas dos consumidores em relação a marcas conhecidas. Já os extrínsecos são as medidas que testam a força das marcas no que se refere à sua sensibilidade a mudanças nas políticas de marketing da empresa e seus concorrentes.

As quatro teorias possuem semelhanças e diferenças que devem ser levadas em consideração, como mostra o quadro 1. São visíveis essas semelhanças e pode-se perceber que, nas quatro teorias, as dimensões voltadas para o consumidor são bem retratadas, enquanto, em relação às dimensões voltadas para os fornecedores e para a empresa, são tratadas, basicamente, por um único autor.

Quadro 1 - Semelhanças encontradas entre as teorias

\begin{tabular}{|c|c|c|c|c|c|}
\hline Dimensões & Itens & Irmscher & $\begin{array}{l}\text { Martin e } \\
\text { Brown }\end{array}$ & $\begin{array}{l}\text { Lassar, } \\
\text { Mittal e } \\
\text { Sharma }\end{array}$ & $\begin{array}{l}\text { Francois e } \\
\text { MacLachlan }\end{array}$ \\
\hline \multirow{8}{*}{ Consumidor } & $\begin{array}{l}\text { Reconhecimento/ } \\
\text { conhecimento - }\end{array}$ & & & & $x$ \\
\hline & Imagem da marca & $x$ & $x$ & $x$ & \\
\hline & Valor percebido & $x$ & $x$ & $x$ & $x$ \\
\hline & Confiança & & $x$ & $x$ & \\
\hline & Compromisso & & $x$ & $x$ & $x$ \\
\hline & $\begin{array}{l}\text { Lealdade do } \\
\text { consumidor }\end{array}$ & $x$ & & & $x$ \\
\hline & Desempenho & & & $x$ & $x$ \\
\hline & Qualidade percebida & & $x$ & & $x$ \\
\hline \multirow{3}{*}{ Fornecedores } & $\begin{array}{l}\text { Relação de } \\
\text { distribuição }\end{array}$ & $x$ & & & \\
\hline & $\begin{array}{l}\text { Dependência } \\
\text { e lealdade do } \\
\text { fornecedor }\end{array}$ & $x$ & & & \\
\hline & Valor percebido & $x$ & & & \\
\hline \multirow{2}{*}{ Empresa } & $\begin{array}{l}\text { Adaptação às } \\
\text { extensões de marca } \\
\text { para outras categorias } \\
\text { e / ou segmentos }\end{array}$ & $x$ & & & \\
\hline & $\begin{array}{l}\text { Proteção contra } \\
\text { a concorrência } \\
\text { (Patentes, marcas } \\
\text { registradas, } \\
\text { inovação). }\end{array}$ & $x$ & & & \\
\hline
\end{tabular}

Fonte: Adaptado de Ramos, 2002.

Delimitando na dimensão do consumidor, foi possível construir o quadro 2 que engloba todas as quatro teorias permitindo uma metrificação mais completa. Mais a frente será elaborada um questionário com base nesse quadro. 
Quadro 2 - Teorias reunidas baseando-se na dimensão do con-

sumidor

\begin{tabular}{|c|c|}
\hline Itens & Medida \\
\hline Percepção & $\begin{array}{l}\text { - Primeira marca mencionada } \\
\text { - Marca é reconhecida } \\
\text { - Recordação espontânea ou sugerida }\end{array}$ \\
\hline Imagem da marca & $\begin{array}{l}\text { - Marca é considerada melhor do que outras do mesmo segmento } \\
\text { - Boa reputação } \\
\text { - Percepção do consumidor sobre a marca } \\
\text { - Quantidade de pros e contras a respeito da marca } \\
\text { - } 0 \text { consumidor se identifica com a marca } \\
\text { - Presença da marca na vida do consumidor } \\
\text { - Relação do consumidor com a marca } \\
\text { - Sentimentos do consumidor sobre a marca }\end{array}$ \\
\hline Valor percebido & $\begin{array}{l}\text { - Preço considerado adequado pelo consumidor } \\
\text { - Existe um bom custo-benefício } \\
\text { - Marca é a preferida entre outras com produtos semelhantes e com } \\
\text { preço igual ou inferior } \\
\text { - } 0 \text { valor fornecido pela marca é tido como superior ao preço pago }\end{array}$ \\
\hline Confiança & $\begin{array}{l}\text { - Confia que ao comprar a marca terá uma experiência igual ou } \\
\text { superior a de compras passadas } \\
\text { - Marca confiável e sem imprevistos } \\
\text { - Acredita que a marca se preocupa com o consumidor }\end{array}$ \\
\hline Compromisso & $\begin{array}{l}\text { - Existe afeição pela marca } \\
\text { - Mesmo com o preço inferior de outras marcas é preferível comprar } \\
\text { dessa. } \\
\text { - Grandes chances de se comprar novamente da mesma marca } \\
\text { quando surgir a necessidade } \\
\text { - Mesmo em produtos semelhantes o consumidor percebe grandes } \\
\text { diferenças entre as marcas }\end{array}$ \\
\hline Qualidade & $\begin{array}{l}\text { - A marca tem o desempenho esperado ou superior } \\
\text { - A marca é vista como tendo uma boa duração } \\
\text { - Qualidade percebida como sendo alta } \\
\text { - Gostos e necessidades dos consumidores são satisfeitos } \\
\text { - Potenciais consumidores desejam adquirir a marca }\end{array}$ \\
\hline $\begin{array}{l}\text { Lealdade do } \\
\text { consumidor }\end{array}$ & $\begin{array}{l}\text { - Proporção de pessoas que usam principalmente ou exclusivamente } \\
\text { a marca }\end{array}$ \\
\hline Desempenho & $\begin{array}{l}\text { - De fácil manuseio } \\
\text { - Espera-se um desempenho bom ou superior. } \\
\text { - Acredita-se que não ocorrerão imprevistos. }\end{array}$ \\
\hline
\end{tabular}

Fonte: Adaptado de Ramos, 2002.

Mensurar o valor de uma marca, por meio das métricas de marketing, é importante para saber se tais investimentos estão gerando retorno e resultados esperados (OLIVEIRA; LUCE, 2011).

\subsection{Modelo e Hipóteses}

As análises realizadas na literatura revelaram os indicadores que formam o modelo deste estudo. Foi realizada uma interação entre os indicadores que explicam a metrificação da marca, gerando um modelo experimental (figura 2) em que os indicadores compromisso, confiança, desempenho, lealdade, percepção, qualidade e valor percebido convergem para a imagem da marca.
Figura 2- Modelo estrutural

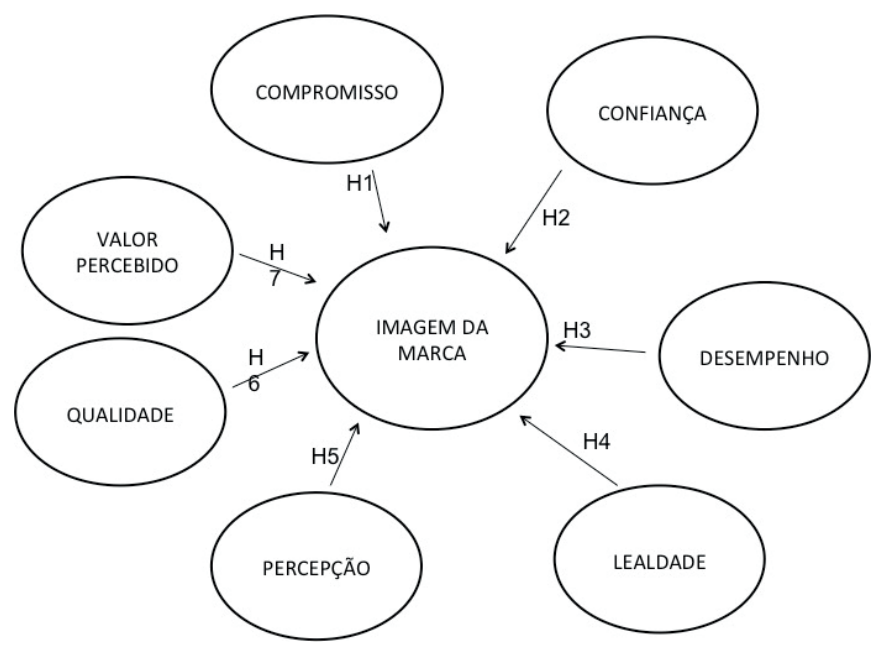

Fonte: Própria.

Assim, as hipóteses deste estudo são:

- $\mathrm{H}_{1}$ - $\mathrm{O}$ compromisso possui um alto grau de influência na imagem da marca

- $\mathrm{H}_{2}$ - A confiança possui um alto grau de influência na imagem da marca

- $\mathrm{H}_{3}$ - $\mathrm{O}$ desempenho possui um alto grau de influência na imagem da marca

- $\mathrm{H}_{4}$ - A lealdade possui um alto grau de influência na imagem da marca

- $\mathrm{H}_{5}$ - A percepção possui um alto grau de influência na imagem da marca

- $\mathrm{H}_{6}-\mathrm{A}$ qualidade possui um alto grau de influência na imagem da marca

- $\mathrm{H}_{7}-\mathrm{O}$ valor percebido possui um alto grau de influência na imagem da marca

\section{Metodologia}

Este trabalho é um estudo descritivo, que, segundo Gil (1989, p. 45), "têm como objetivo primordial a descrição das características de determinada população ou fenômeno, ou o estabelecimento de relações entre variáveis". Sua abordagem é quantitativa.

Inicialmente, foi realizada a busca dos indicadores relacionados à marca e os conceitos complementares da metrificação. A base de dados utilizada foi a Scielo (disponível em: <www.scielo.org >), pesquisado entre os anos de 1965 até 2014. Foram encontrados 3.971 artigos, destes foram selecionados cerca de 36 artigos segundo seu fator de impacto e relevância para compor este estudo. 
O instrumento para coleta de dados foi o questionário em espanhol validado por Ramos (2002) sobre os modelos multidimensionais para a medição do valor da marca que foi adaptado e validado na Língua Portuguesa $(f \boldsymbol{c}=\mathbf{0 , 8 5 8})$. O levantamento foi feito por meio de um questionário com 32 perguntas objetivas e uma subjetiva. A escala utilizada foi à escala Likert de 5 opções: Concordo, Concordo moderadamente, Neutro, Discordo moderadamente e Discordo.

O critério de inclusão foram estudantes do curso de administração de uma Universidade particular do Distrito Federal. O universo da pesquisa foi de 860 alunos. O cálculo da amostra utilizada para margem de confiança de $95 \%$ e erro amostral de 5\%, foi de 266 estudantes. A amostra foi não probabilística Foram realizados 450 questionários, porém, algumas respostas em branco invalidaram parte da amostra, sendo utilizados apenas 381 questionários válidos.

A análise da pesquisa foi feita por meio do software SPLS (Smart Partial Least Square), que é muito utilizado para pequenas amostras e validação de instrumentos. O SPLS utiliza a análise multivariada por meio dos múltiplos quadrados parciais. Ele é mais flexível por ser um método de segunda ordem, o que ajuda a explicar cenários de pesquisa em que a teoria ainda não foi consolidada (RAMIREZ; MARIANO; SALAZAR, 2014).

Os dados obtidos dos questionários foram organizados em uma planilha no Excel e então inseridos no programa SmartPLS. Com isso o software pôde calcular o modelo criado, gerando informações de correlações múltiplas entre as variáveis latentes.

\section{Resultados e análise}

\subsection{A marca Harley-Davidson}

A marca Harley-Davidson foi escolhida para este trabalho por ser uma marca forte e conhecida. Mesmo tendo um público alvo bem especifico, ela consegue ir além de seus principais consumidores e atingem um grande público.

Criada em 1903, pelos amigos Arthur Davidson e William S. Harley, no município de Milwaukee nos Estados Unidos, a Harley-Davidson é a marca de motocicletas mais importante no mundo. Em 1920, a empresa já era a maior fabricante de motocicletas do Mundo e foi à única fabrica de motocicletas que, além de sobreviver a duas grandes guerras mundiais, resistiu à chegada das ninjas, como são conhecidas as motos japonesas que, ao entrar no mercado em 1982, ofereceu novas combinações de preços, além de modelos de motos com menores cilindradas. Em contrapartida, a Harley percebeu um gancho como marca de tradição e, em vez de tentar acompanhar as ninjas, soube contornar a situação ao se valorizar e consolidar seu diferencial e passaram a focar no estilo clássico de seus produtos, atingindo, assim, um público alvo específico.

Com assento baixo, guidão alto, conforto do motorista sendo mais valorizado que a velocidade alcançada, já que são motos grandes e não foram projetadas para atingir altas velocidades, além de seu estilo retrô, a Harley, também, é conhecida por sua estabilidade e seu motor de dois cilindros em $\mathrm{V}$, que proporciona elasticidade e um ótimo torque mesmo em baixas rotações. Outra característica única de suas motos é o ronco de seus motores cromados, que são projetados para emitirem um som característico da marca, fortalecendo ainda mais sua identidade.

Essa identidade é tão forte que até quem não é consumidor ou motociclista consegue criar um conjunto de imagens associados à marca, consolidando, assim, o processo de memorização da mesma.

Atualmente, a Harley-Davidson é uma das marcas de referência mundial no motociclismo, produz cerca de 280 mil motos por ano e está presente em todos os continentes. Com 1300 postos de vendas espalhados pelo mundo, oferece mais de 28 modelos diferentes de motos, além de roupas e acessórios que, também, possuem a identidade da marca. A Harley conseguiu consolidar sua marca e fidelizar clientes ao deixar de vender, apenas, motos de qualidade, mas sim um estilo de vida e um sonho de liberdade, pois, como diz sua missão,

Código de conduta profissional da Harley-davidson

Realizamos sonhos inspirados nas estradas espalhadas pelo mundo todo, construindo motocicletas extraordinárias e dando ao cliente a oportunidade de viver uma experiência inesquecível. Abastecemos nossos clientes com a mais pura paixão por liberdade, para que cada um deles tenha a chance de expressar sua individualidade. (HARLEY-DAVIDSON, 2013, 6.)

A análise dos dados foi dividida em duas etapas, a primeira de caráter demográfico, em que são apresentas as informações a respeito do gênero, faixa etária, classe social e interesse do público participante. Já na segunda etapa, será apresentada a validação do modelo e as considerações. 


\subsection{Dados demográficos}

No gráfico 1 , estão registrados a quantidade de respondentes referentes a seu respectivo gênero. De 381 questionários tabulados, 243 respondentes pertencem ao sexo masculino, quase o dobro de respondentes do sexo feminino que obteve apenas 138 representantes.

Gráfico 1 - Respondentes por gênero

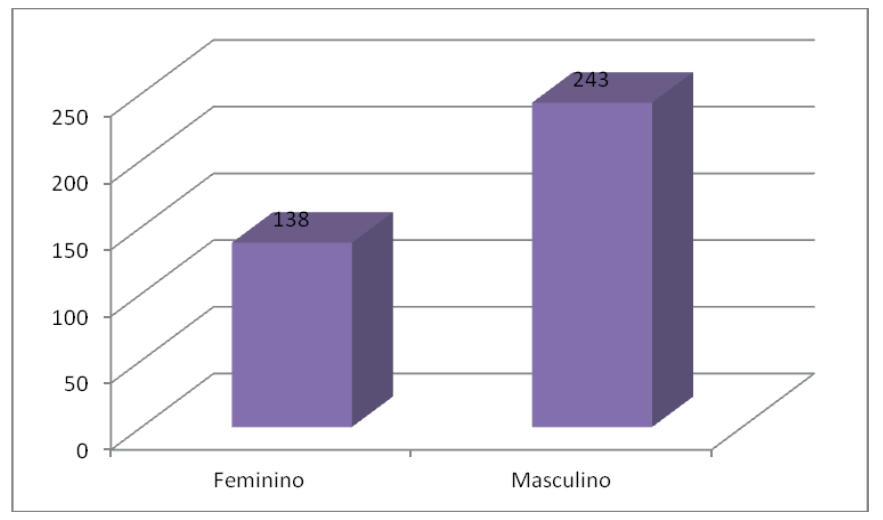

Fonte: Própria.

No gráfico 2, observa-se a faixa etária de 20 a 30 anos com números mais expressivos, totalizando 231 respondentes, seguido de 133 respondentes com idade abaixo dos 20 anos. Isso pode ser explicado pelo fato de ser a idade média dos estudantes universitários alvo da amostra determinada.

Gráfico 2 - Respondentes por idade

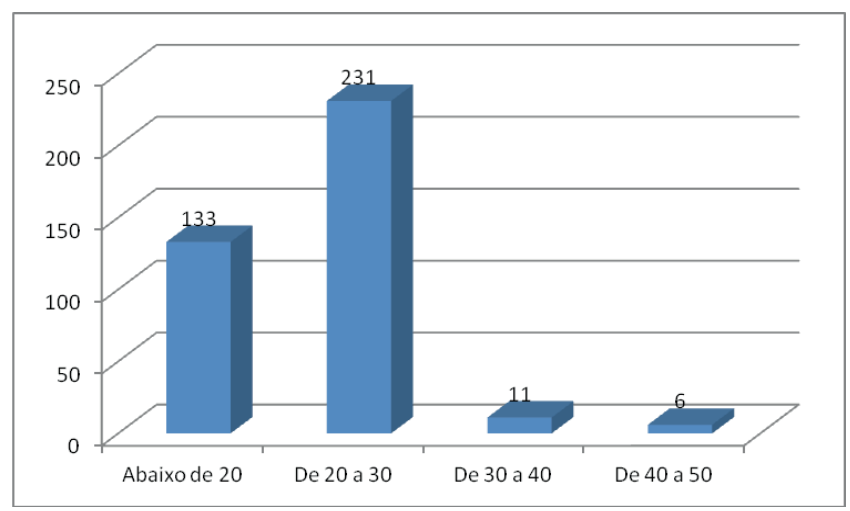

Fonte: Própria.

A renda mensal mais significativa encontrada, com 229 respondentes, foi acima de $\mathrm{R} \$ 9.745,00$, e pode ser observadas no gráfico 3. Segundo a Fundação Getulio Vargas (2011) uma renda mensal acima de $\mathrm{R} \$ 9.745,00$ são de pertencentes da classe A.
Gráfico 3 - Respondentes por classe social

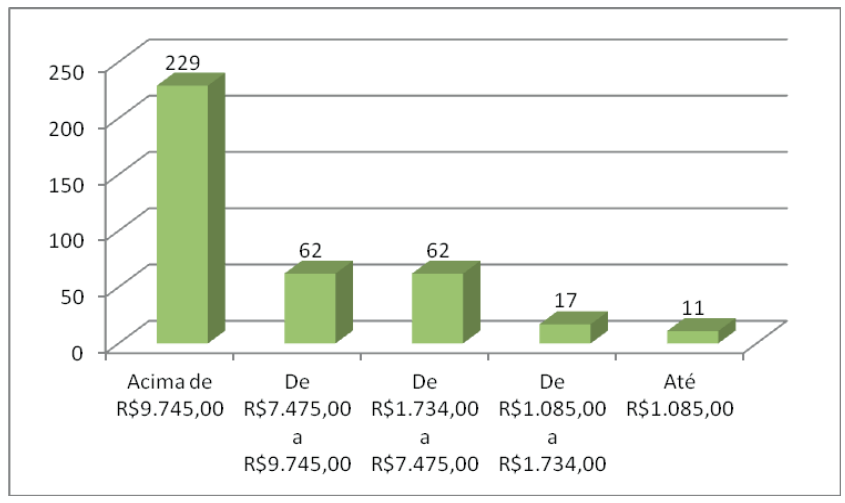

Fonte: Própria.

Por fim, ao avaliar o grau de interesse e intimidade que os respondentes possuem por motos, no gráfico 4 é possível perceber que 203 respondentes possui sim algum tipo de interesse pelo produto, contra 178 que não pretendem ter uma moto algum dia.

Gráfico 4 - Respondentes por nível de interesse pelo produto

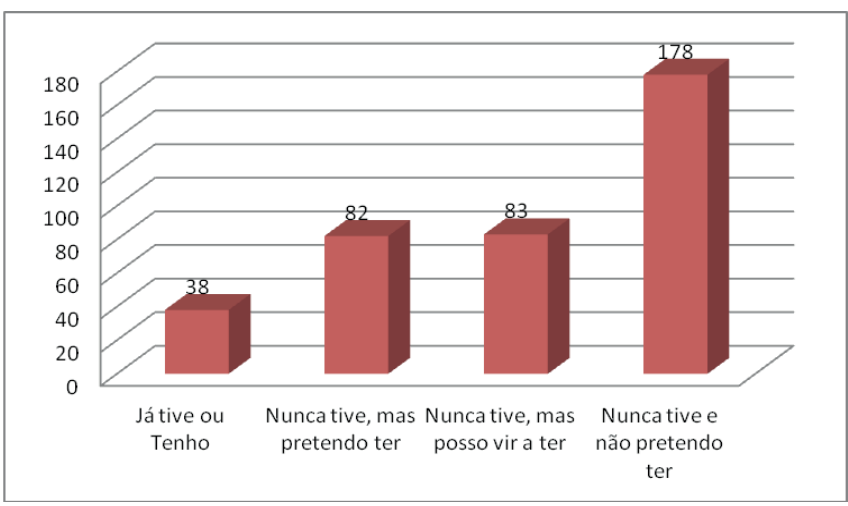

Fonte: Própria

\subsection{Modelo estrutural}

Após identificar o cenário demográfico em que a pesquisa se encontra, procedem-se as análises de confiabilidade e validade do instrumento, assim como a valoração do modelo por meio do programa SmartPLS (Smart Partial Least Square).

Ramirez, Mariano e Salazar (2014) explicam que o primeiro passo para a analise é criar o modelo estrutural com base nas relações entre as variáveis que podem ser encontradas na literatura. Após desenhar as interações do modelo por meio das relações entre as variáveis, realiza-se o cálculo por meio do programa estatístico. 
Figura 3 - Modelo de equações estruturais.

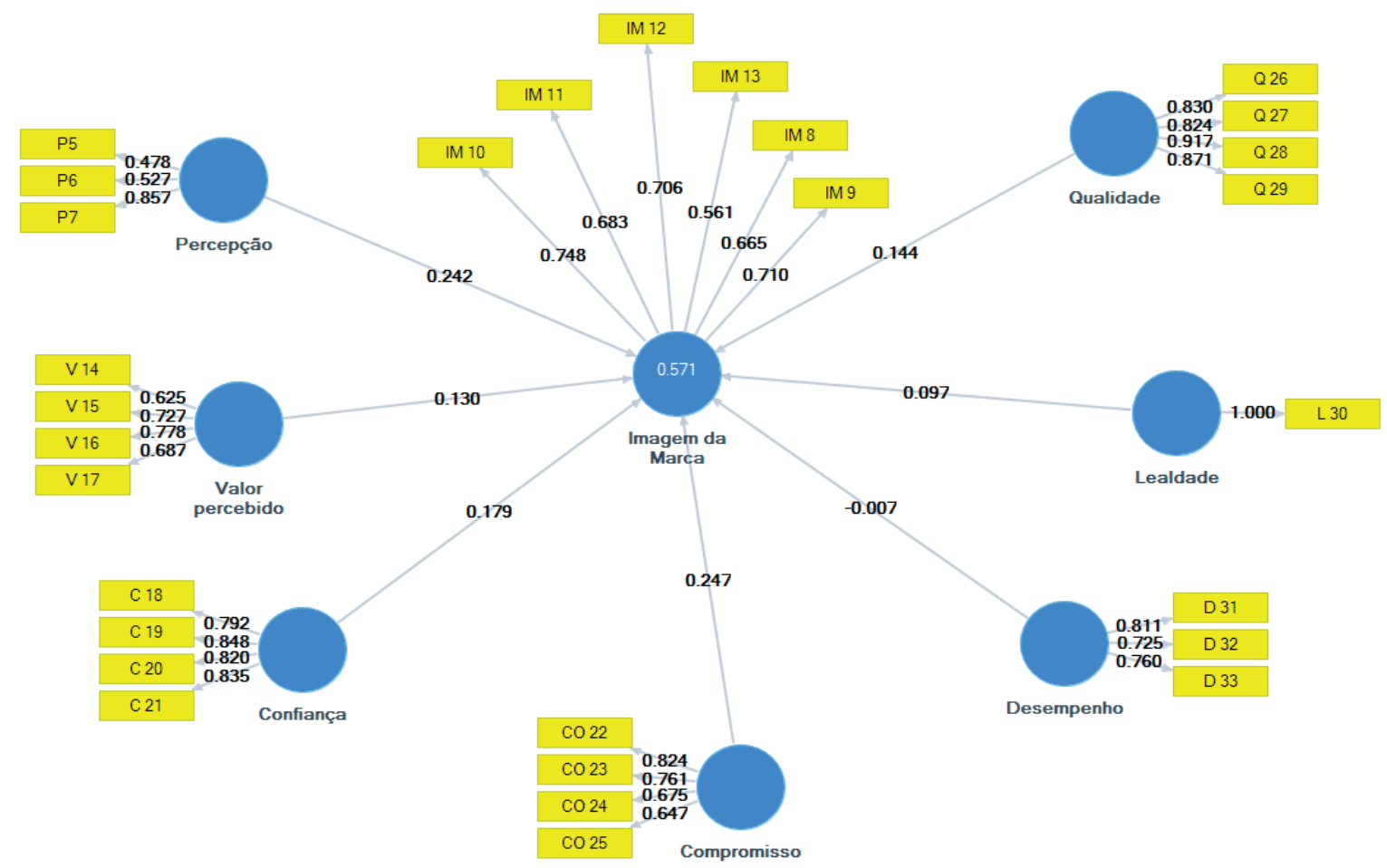

Fonte: SmartPLS.

No modelo (figura 3), é possível perceber as relações entre as variáveis que estão interligadas. No modelo os retângulos são os indicadores, perguntas presentes no questionário, cada um diretamente relacionado à variável latente a qual explicam representada pelos círculos. As setas que ligam as variáveis a seus itens possuem números que significam os valores de confiabilidade expressos por correlação simples e a variável latente juntamente aos seus indicadores representam um constructo. Já os betas são os números sob as setas que ligam as variáveis a outras variáveis, eles explicam a influência que existe entre uma variável e outra (independente sobre dependente) e finalmente, os $\mathrm{R}^{2}$ que são os valores localizados dentro das variáveis latentes, e significa o grau de predição entre variável independente e dependente. Outros coeficientes existentes no modelo serão apresentados posteriormente.

Após a formação do modelo, a analise é realizada em duas etapas. Primeiramente quanto à confiabilidade do modelo e de seu instrumento, e, então, quanto ao grau de predição das variáveis dependentes e o grau de influência das variáveis independentes.

\subsubsection{Confiabilidade e validade do modelo e instru- mento}

A construção de qualquer instrumento de medi- da exige cuidados que garantem a segurança quanto aos resultados encontrados. A confiabilidade e validade de um instrumento garantem que essas medidas sejam replicáveis e consistentes, gerando, sempre, os mesmos resultados, além de representarem, precisamente, as características que se pretendem medir (MARTINS, 2006). A Confiabilidade é medida de maneira individual por meio da fiabilidade de item e de maneira conjunta por meio da confiabilidade composta, uma medida alternativa, mais flexível para pesquisas iniciais do que o Alpha de Cronbach, a Validade por sua vez é medida pelos coeficientes de AVE e variância discriminante.

Para se chegar ao modelo inicial, foi realizado o estudo da confiabilidade de item por meio da correlação entre cada um dos itens individualmente e a variável latente correspondente. Na literatura, o valor estabelecido para correlações aceitáveis é de 0,707 , sendo aceito por alguns autores até 0,55 para pesquisas iniciais (RAMIREZ; MARIANO; SALAZAR, 2014). Sendo assim, pode-se perceber que o indicador $\mathrm{P} 5$, que se refere a uma pergunta do questionário, possui uma carga inferior a 0.5 , que é o valor mínimo aceitável para a confiabilidade, não passando, então, na validade de item. Portanto, este item foi eliminado do modelo. 
Ao se eliminar um item de um modelo, é possível adequar o instrumento e consequentemente o próprio modelo, em um processo chamado de depuração (CHIN, 1998). A questão eliminada pode não ter atingido a confiabilidade necessária por apresentar um formato diferente das outras, era uma questão aberta que após a resposta dos respondentes era transformada no modelo de escala Likert, e isso alterou a estrutura da questão. Sendo assim, é possível em próximas pesquisas melhorar essa questão para se atingir o resultado esperado ou até mesmo substitui-la por algo semelhante que possa ser encontrado na literatura.

Feita as alterações necessárias, o modelo foi executado mais uma vez, mas agora sem o item P5, gerando os seguintes resultados:

Figura 4 - Modelo de equações estruturais.

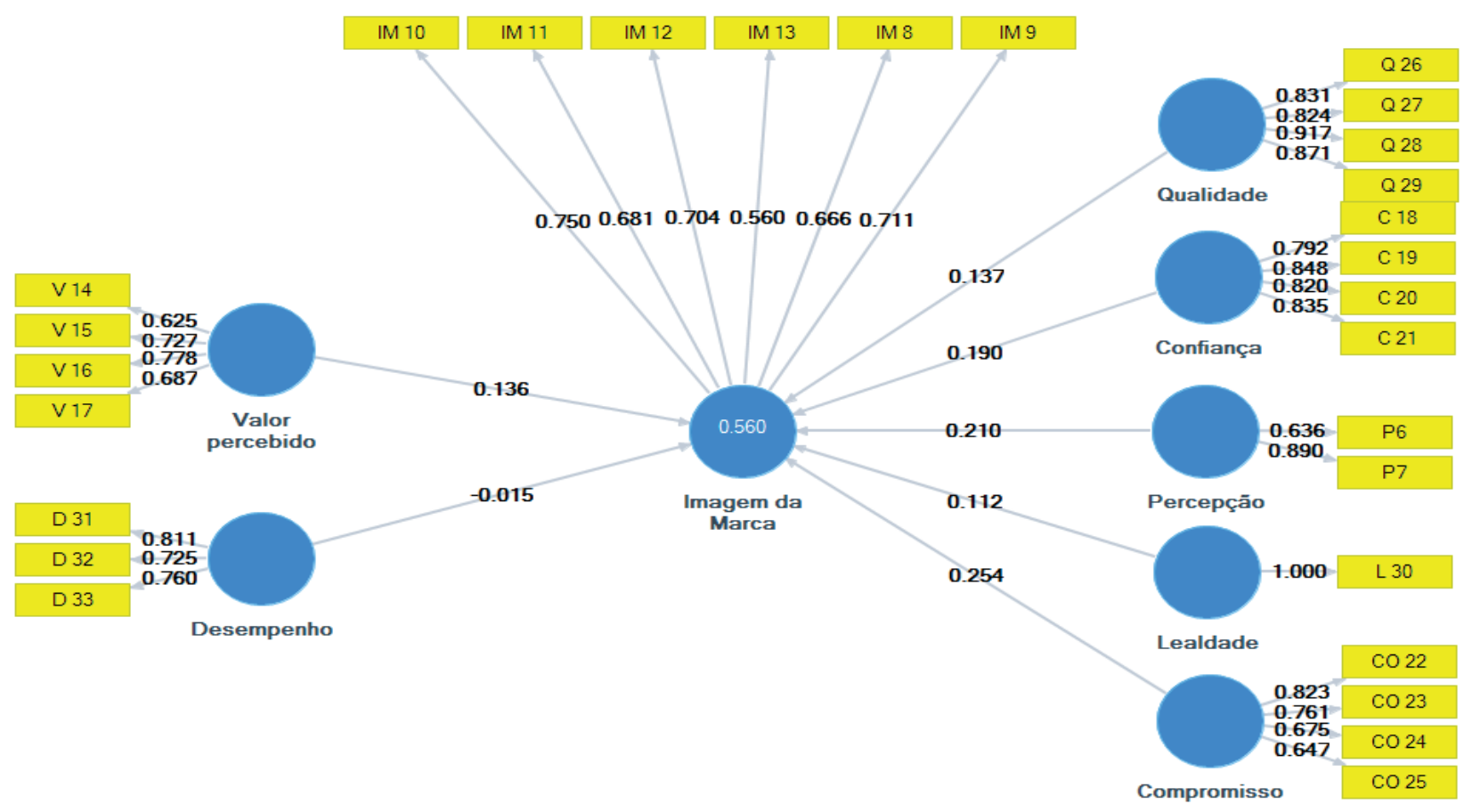

Fonte: SmartPLS

Como mostrado na figura 4, todos os itens apresentam confiabilidade maior que 0,5. Falk e Miller (1992) explicam que, para identificar se as perguntas do questionário estão realmente correlacionadas com sua variável latente, a carga mínima aceitável é $\lambda \geq 0,55$.

$\mathrm{O}$ segundo teste de confiabilidade está ligado à variável latente, ou constructo. Ela vai mostrar se todos os indicadores são suficientes para que o conceito seja explicado, apresentando, assim, uma consistência interna. Nesse caso será usado a Confiabilidade Composta em lugar do Alpha de Cronbach, que costuma ser o mais utilizado, já que esta oferece valores mais flexíveis que são importantes para pesquisa iniciais (CHIN, 1998). No gráfico 5 , é possível perceber que o resultado da pesquisa apresenta a Confiabilidade Composta com valores superiores
0,6. Esses valores demonstram que os indicadores utilizados na pesquisa conseguem medir suas variáveis latentes da forma correta, permitindo um modelo confiável.

Gráfico 5 - Confiabilidade composta.

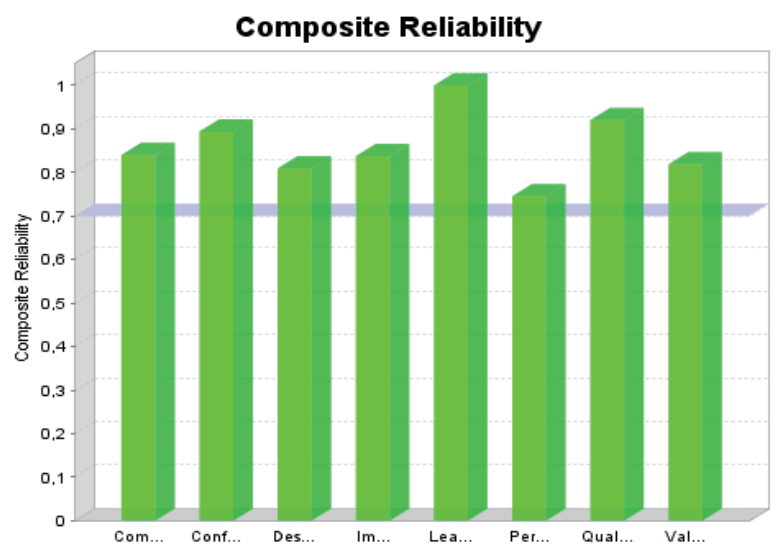

Fonte: SmartPLS 
Finalmente, por meio dos resultados de confiabilidade de item e os coeficientes de confiabilidade satisfatórios com uma média de 0,858 , é possível confiar no modelo apresentado.

Terminado os coeficientes de confiabilidade, é o momento de descobrir a validade do constructo. $\mathrm{O}$ primeiro coeficiente utilizado para isso é a Variância Extraída Média (AVE), e, por meio dela, é possível dizer que os indicadores estão medindo sua variável latente e não outras variáveis presentes no modelo. Espera-se que o valor mínimo seja de $A V E \geq 0,5$. Observando-se, então, o gráfico 6, é possível afirmar que todos os indicadores medem sua variável latente, já que os valores encontrados para AVE são maiores que 0,5 .
Gráfico 6 - Valores de AVE

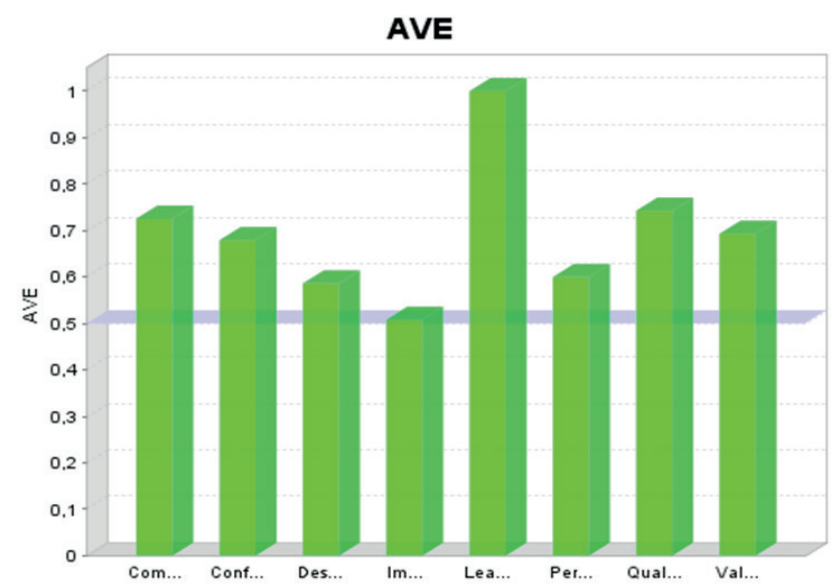

Fonte: SmartPLS

Após calcular a variância extraída média, mede-se a variância discriminante. Esta irá mostrar a independência de cada variável, ou seja, se cada constructo é realmente diferente dos demais. O cálculo é realizado com base na raiz quadrada de AVE (em negrito) e espera-se que seu resultado seja maior que os valores que vem no quadro 3.

Quadro 3 - Variável discriminante

\begin{tabular}{|c|c|c|c|c|c|c|c|c|}
\hline & Compromisso & Confiança & Desempenho & $\begin{array}{l}\text { Imagem da } \\
\text { Marca }\end{array}$ & Lealdade & Percepção & Qualidade & Valor percebido \\
\hline Compromisso & 0,852 & & & & & & & \\
\hline Confiança & 0,519 & 0,824 & & & & & & \\
\hline Desempenho & 0,473 & 0,572 & 0,766 & & & & & \\
\hline Imagem da Marca & 0,624 & 0,611 & 0,504 & 0,713 & & & & \\
\hline Lealdade & 0,522 & 0,403 & 0,505 & 0,448 & 1,000 & & & \\
\hline Percepção & 0,346 & 0,394 & 0,284 & 0,470 & 0,136 & 0,774 & & \\
\hline Qualidade & 0,435 & 0,688 & 0,546 & 0,546 & 0,301 & 0,392 & 0,862 & \\
\hline Valor percebido & 0,391 & 0,412 & 0,508 & 0,475 & 0,393 & 0,221 & 0,382 & 0,833 \\
\hline
\end{tabular}

Fonte: Própria.

Sendo assim, pode-se dizer que o modelo e o instrumento são confiáveis e válidos.

\subsubsection{Valoração do modelo estrutural}

Para a valoração do modelo estrutural são realizadas duas análises através dos coeficientes de $\mathrm{R}^{2}$ e $\beta$. O R ${ }^{2}$ mede o poder de predição das variáveis independentes sobre as variáveis dependentes e o $\beta$ revela o grau de influência de uma variável sobre a outra.

Todas as variáveis independentes (Compromisso, Confiança, Desempenho, Lealdade, Percepção, Qualidade e Valor percebido) predizem a Imagem da Marca em
$56 \%$ o que é um valor muito expressivo, já que o valor mínimo de $\mathrm{R}^{2}$ precisa ser de até 10\% (FALK; MILLER,1992). Sendo assim, pode-se afirmar que a variável latentes é bem explicada pelos constructos que as prediz.

A segunda valoração está relacionada à influência de cada variável na variável predita, ou seja, o coeficiente path $(\beta \geq 0,2)$. Os valores de Beta são apresentados no modelo pelas flechas que ligam cada constructo (CEPEDA; ROLDÁN, 2004). No modelo apresentado, percebe-se que, entre os sete conectores, apenas dois dos caminhos atingem o valor mínimo exigido na literatura de $\beta \geq$ 
0,2, que são o de Compromisso e Percepção, sendo os caminhos referentes à Confiança, Qualidade, Valor percebido, Lealdade e Desempenho hipóteses não suportadas.

Quadro 4 - Valores de Beta

\begin{tabular}{|c|cccc|}
\hline & $\begin{array}{c}\text { Imagem da } \\
\text { Marca( } \beta \text { ) }\end{array}$ & Latent Correl & $\begin{array}{c}\text { Peso da } \\
\text { Influência }\end{array}$ & Hipótese \\
\hline Compromisso & 0,25 & 0,624 & $16 \%$ & H1 \\
\hline Confiança & 0,19 & 0,611 & $11,5 \%$ & H2 \\
\hline Desempenho & $-0,01$ & 0,504 & $0,5 \%$ & H3 \\
\hline Lealdade & 0,11 & 0,448 & $5 \%$ & H4 \\
\hline Percepção & 0,21 & 0,470 & $10 \%$ & H5 \\
\hline Qualidade & 0,13 & 0,546 & $7 \%$ & H6 \\
\hline $\begin{array}{l}\text { Valor } \\
\text { percebido }\end{array}$ & 0,13 & 0,475 & $6 \%$ & H7 \\
\hline
\end{tabular}

Fonte: Própria.

Assim, pode-se perceber que os Betas de $\mathrm{H} 1 \mathrm{e}$ H5 são superiores a 0,2, podendo ainda agregar, devido à aproximação, o H2, por se tratar de um estudo inicial.

\section{Considerações finais}

O problema da pesquisa foi responder quais fatores antecedentes que mais influenciam a da imagem da marca. Observando os resultados, sugere-se que o fator de maior influencia sobre a imagem da marca é o compromisso que o consumidor tem com a marca (16\%), seguido da confiança $(11,5 \%)$ e da percepção da marca (10\%).

Sendo assim, quanto mais a marca é percebida na vida dos consumidores e quanto maior for à confiança e compromisso que estes sentem pela marca, melhor será imagem da mesma no mercado em que atua. Assim, o objetivo deste artigo, que foi identificar o grau de influência dos fatores antecedentes à imagem da marca, foi alcançado.

Com a utilização do programa SmartPLS, foi possível confirmar as hipóteses $H 1$, H2 e H5 como significativas, as demais não foram confirmadas. Esta não confirmação pode ser explicada pelo fato de muitos conhecerem a marca Harley-Davidson pela visibilidade e importância que ela conquistou durante todos esses anos de existência, mas nem todos costumam ter um contato realmente direto com o produto, impossibilitando avaliar questões como Desempenho, Qualidade, Lealdade, Confiança e Valores, outro fator possível pode ser o público alvo da amostra formado por estudantes universitários que muitos, ainda, não possuem veículos automotores, apenas realizando um conceito perceptivo do produto.

O estudo realizado apresentou limitações quanto à população onde foi aplicada a pesquisa. $\mathrm{O}$ ideal seria uma amostra mais diversificada. Como sugestão para trabalhos futuros, aconselha-se o uso do instrumento validado neste trabalho a outras populações e a amostras maiores para obtenção de dados mais contundentes. Também é aconselhado o estudo individual da variável "Percepção" de modo que seja incrementada com mais indicadores.

\section{Referências}

AAKER, D. A. Managing brand equity: capitalizing on the value of brand name. New York: Free Press, 1991.

AMERICAN MARKETING ASSOCIATION. Disponível em: <http://www.ama.org>. Acesso em: 01 maio 2015.

ANSOFF, H. I. Corporate strategy. Harmondsworth: Penguin, 1965.

AZEvEDO, B. M. M.; ARAUjO, M. M. C. N. A Marca Harley-Davidson no Brasil: o "sonho" e os entraves à reprodução de uma estratégia de sucesso. In: ENCONTRO NACIONAL DE ESTUDOS DO CONSUMO, 5., 2010, Rio de Janeiro. Anais...Rio de Janeiro: ENEC, 2010.

BUAINAIN A. M.; CARVAlHO S. M. P. Propriedade intelectual em um mundo globalizado. In: WIPO INTERNATIONAL CONFERENCE ON INTELLECTUAL PROPERTY, TRADE, TECHNOLOGICAL INNOVATION AND COMPETITIVENESS, 2000, Rio de Janeiro. Anais... Rio de Janeiro, 2000.

CAMARGOS, M. A.; DIAS, A. T. Estratégia, administração estratégica e estratégia corporativa: uma síntese teórica. Caderno de Pesquisas em Administração, São Paulo, v. 10, n. 1, p. 27-39, 2003.

CEPEDA, G.; ROLDÁN, J. L. Aplicando en la práctica la técnica PLS en la Administración de Empresas. In: CONOCIMIENTO Y COMPETITIVIDAD. CONGRESO 
NACIONAL ACEDE, 14., 2004, Espanha. Anais... Espanha, 2004. p. 74-78.

CHIN, W. W. Comentário: questões e opinião sobre modelagem de equações estruturais: MIS Quaterly, 1998.

COSTA, L. S.; ALMEIDA, V. M. C. Valor da marca: teste empírico da importância das dimensões formadoras do valor da marca na perspectiva do consumidor no contexto brasileiro. Revista Brasileira de Marketing, São Paulo, v. 11, n. 2, p. 43-68, maio/ago. 2012.

FALK, R. F.; MILLER, N. B. A primer for soft modeling. Akron: University of Akron Press, 1992.

FARIA A.; GUEDES A. Movimento cultural nos estudos organizacionais: uma abordagem interdisciplinar focada no consumo e na globalização. Cadernos EBAPE.BR, v. 3, n. 1, mar. 2005.

FEITOSA, J. G. Marketing empresarial: o poder da marca. Piauí: UESPI, 2009.

FRANÇOIS, P.; MACLACHLAN, D. L. Ecological validation of altemative customer-based brand strength measures. International Journal of Research in Marketing, v. 12, p. 321-332, nov. 1995.

FUNDAÇÃO GETÚlIO VARGAS. Centro de políticas sociais. Disponível em: <http://cps.fgv.br/node/3999>. Acesso em: 01 maio 2015.

GHEMAWAT, P. Sustainable advantage. Harvard Business Review, v. 64, n. 5, p. 53-58, Sep./Oct. 1986.

GIL, A. C. Métodos e técnicas de pesquisa social. 2. ed. São Paulo: Atlas, 1989.

IRMSCHER, M. Modeling the brand equity concept. Marketing and Research Today, v. 21, p. 102-110, May 1993.

KAYO, E. K.; KIMURA, H.; MARTIN, D. M. L.; NAKAMURA, W. T. Ativos intangíveis, ciclo de vida e criação de valor. RAC, São Paulo, v. 10, n. 3, p. 73-90, jul./ set. 2006.

KELLER, K. L. Conceptualizing, measuring and managing customer-based brand equity. Journal of marketing, Chicago, Chicago, v. 57, p. 1-22, jan. 1993.
KOTLER, P. Administração de marketing: análise, planejamento, implementação e controle. 5. ed. São Paulo: Atlas, 1998.

KOTLER, P.; KELLER, K. L. Administração de marketing. 12. ed. São Paulo: Pearson, 2006.

LANZA, A. B. R.; CASIELLES, R. V.; ARGÜELLES, V. I. El valor de marca: perspectivas de análisis y criterios de estimación. Cuadernos de Gestión, local, v. 1, n. 2, ene. 2002.

LASSAR, W.; MITTAL, B. Y SHARMA, A. Measuring customer-based brand equity. Journal of Consumer Marketing, v. 12, n. 4, p. 11-19, 1995.

MAGALHÃES, T. A. Valor da marca para o consumidor: um estudo empírico. Belo Horizonte: FUMEC, 2006.

MARTIN, G. S.; BROWN, T. J. In search of brand equity: the conceptualization and measurement of the brand impression construct. American Marketing Association, Chicago, v. 2, p. 431-38, 1990.

MARTINS, J. R. Branding: um manual para você criar, gerenciar e avaliar marcas. 3. ed. São Paulo: Global Brands, 2006.

MOTOCLUBE. História da Harley Davidson. Disponível em: <http://motoclube.com/ artigos/historia-harley-davidson $>$. Acesso em: 11 maio 2015.

OLIVEIRA, M. O. R; LUCE, F. B. O valor da marca: conceitos, abordagens e estudos no brasil. REAd, Rio Grande do Sul, v. 69, n. 2, p. 502-529, maio/ago., 2011.

PEDRO, M. O valor da marca. Revista Portuguesa de Marketing, Porto, v. 9, 1999.

PEREIRA, C. B.; TOLEDO, G. L.; TOLEDO, L. A. Considerações sobre o conceito de marketing teoria e prática gerencial. REVISTA OઐS, Salvador, v. 16, n. 50, p. 519543, jul./set. 2009.

PUPO, F. P.; BOTELHO, D. Conhecimento e uso de métricas de marketing. Revista PCA, Rio de Janeiro, v. 5, n. 1, p. 38-55, jan./abr. 2011.

RAMÍREZ, P. E.; MARIANO, A. M.; SALAZAR, E. A. Propuesta Metodológica para aplicar modelos de ecua- 
ciones estructurales con PLS: el caso del uso de las bases de datos científicas en estudiantes universitários. In: CONGRESSO INTERNACIONAL DE ADMINISTRAÇÃO - ÉTICA E TRANSPARÊNCIA NAS ORGANIZAÇÕES, Ponta Grossa. Anais do ADMPG, 2014. Ponta Grossa: Estúdio Texto, 2014.

RAMOS, V. Odelos multidimensionales para la medición del valor de marca. Investigaciones Europeas, v. 8, n. 3, p. 13-44, 2002.

RUST, R. T.; ZEITHMAL, V. A.; LEMON, K. N. O valor do cliente: o modelo que está reformulando a estratégia. Porto Alegre: Bookman, 2001.

SAMPAIO, R. Marcas de A a Z: como construir e manter marcas de sucesso: um guia para fazer da sua marca a principal força do seu negócio. Rio de Janeiro: Campus, 2002.

SCHULTZ, D. E; BARNES, B. E. Campanhas estratégicas de comunicação de marca. Rio de Janeiro: Qualitymark, 2001.
SULLIVAN JR, P. H.; SULLIVAN, P. H. Valuing intangibles companies: an intellectual capital approach. Journal of Intellectual Capital, California, v. 1 n. 4, p. 328-340, 2000.

TAVARES, M. C. A força da marca: como construir e manter marcas fortes. São Paulo: Harbra, 1998.

TOALDO, A. M. M.; LUCE, F. B. Estratégia de marketing: contribuições para a teoria em marketing. Revista de Administração de Empresas, out./dez. 2006.

VALORES COTIDIANOS. Código de conduta profissional da Harley-Davidson. Disponível em: <http://media. corporate-ir.net/media_files/IROL/87/87981/Code_of_ Conduct-Portuguese.pdf>. Acesso em: 11 maio 2015.

VASCONCELOS, F. C.; BRITO, L. A. L. Vantagem competitiva: o construto e a métrica. Revista de Administração de Empresas, abr./jun., 2004.

VASCONCELOS, F. C.; CYRINO, Á. B. Vantagem competitiva: os modelos teóricos atuais e a convergência entre estratégia e teoria organizacional. Revista de Administração de Empresas, v. 40, n. 4, out./dez. 2000.

\section{Anexo}

Anexo A - Publicações sobre valor da marca

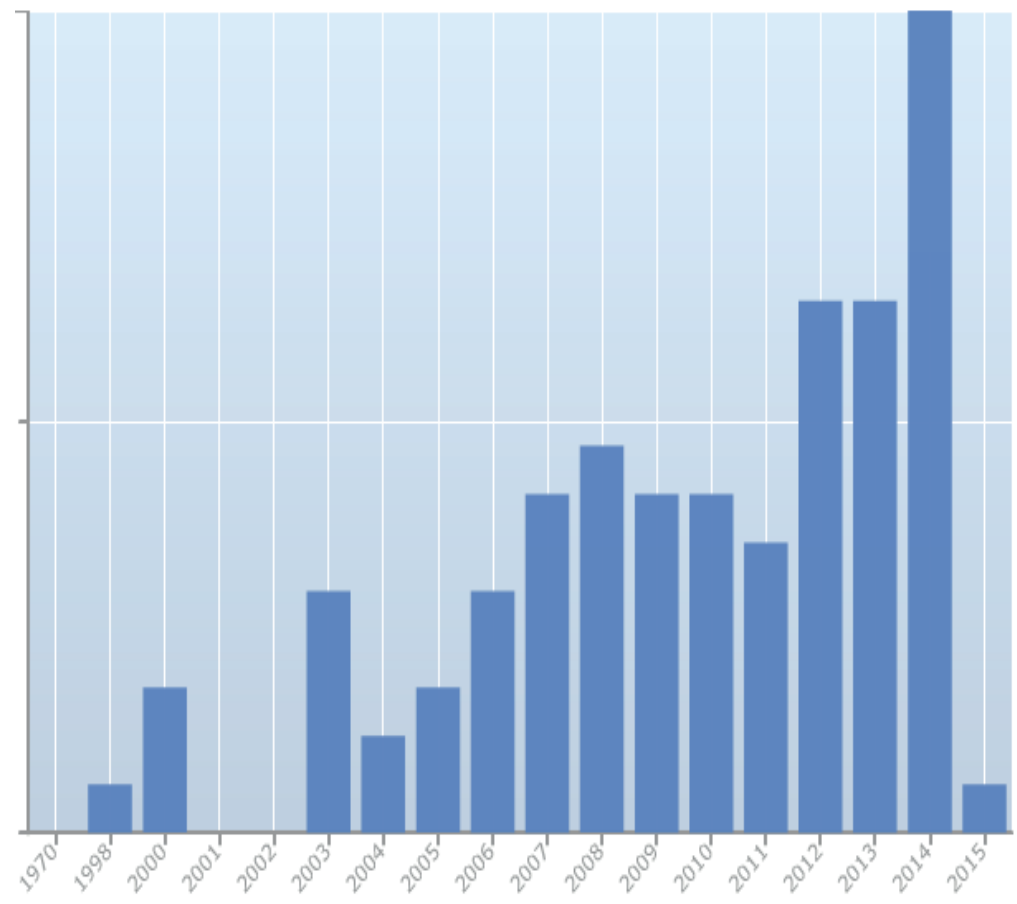

